\title{
Energy transformations and dissipation of nonlinear internal waves over New Jersey's continental shelf
}

\author{
E. L. Shroyer, J. N. Moum, and J. D. Nash \\ College of Oceanic and Atmospheric Sciences, Oregon State University, Corvallis, OR, USA \\ Received: 30 April 2010 - Revised: 13 July 2010 - Accepted: 14 July 2010 - Published: 3 August 2010
}

\begin{abstract}
The energetics of large amplitude, high-frequency nonlinear internal waves (NLIWs) observed over the New Jersey continental shelf are summarized from ship and mooring data acquired in August 2006. NLIW energy was typically on the order of $10^{5} \mathrm{Jm}^{-1}$, and the wave dissipative loss was near $50 \mathrm{~W} \mathrm{~m}^{-1}$. However, wave energies (dissipations) were $\sim 10(\sim 2)$ times greater than these values during a particular week-long period. In general, the leading waves in a packet grew in energy across the outer shelf, reached peak values near $40 \mathrm{~km}$ inshore of the shelf break, and then lost energy to turbulent mixing. Wave growth was attributed to the bore-like nature of the internal tide, as wave groups that exhibited larger long-term (lasting for a few hours) displacements of the pycnocline offshore typically had greater energy inshore. For ship-observed NLIWs, the average dissipative loss over the region of decay scaled with the peak energy in waves; extending this scaling to mooring data produces estimates of NLIW dissipative loss consistent with those made using the flux divergence of wave energy. The decay time scale of the NLIWs was approximately $12 \mathrm{~h}$ corresponding to a length scale of $35 \mathrm{~km}(O(100)$ wavelengths). Imposed on these larger scale energetic trends, were short, rapid exchanges associated with wave interactions and shoaling on a localized topographic rise. Both of these events resulted in the onset of shear instabilities and large energy loss to turbulent mixing.
\end{abstract}

\section{Introduction}

In the coastal ocean, the formation of nonlinear internal wave (NLIW) packets is frequently attributed to tidal interaction with topography (e.g., Apel et al., 1985; New and Pingree,

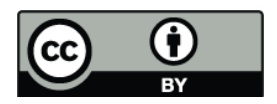

Correspondence to: E. L. Shroyer (eshroyer@whoi.edu)
1992; Small et al., 1999; Ramp et al., 2004). As such, these large amplitude, relatively high-frequency waves represent a step in the cascade of energy from large-scale tidal motions down to small-scale turbulent mixing. The energy in the waves that is available for conversion to mixing is the sum of the kinetic energy and the available potential energy. The kinetic energy is defined as

$$
\begin{aligned}
\mathrm{KE} & =\int_{x_{1}}^{x_{2}} \int_{-H}^{0} E_{\mathrm{k}} d z d x \\
& =\int_{x_{1}}^{x_{2}} \int_{-H}^{0} \frac{1}{2} \rho_{0}\left(u^{\prime 2}+w^{\prime 2}\right) d z d x,
\end{aligned}
$$

and available potential energy is

$\mathrm{APE}=\int_{x_{1}}^{x_{2}} \int_{-H}^{0}(\rho-\bar{\rho}) g z d z d x$

where integration limits extend from the bottom, $z=-H$, to the surface, $z=0$, and across the wave. In the above expressions, $E_{\mathrm{k}}$ is the kinetic energy density for a wave with perturbation velocities $u^{\prime}$ and $w^{\prime}, \rho_{0}$ is the average density, and $\bar{\rho}$ is the reference density, defined by the state of minimum potential energy (Gill, 1982; Shepherd, 1993; Winters et al., $1995)$. The total, $E \equiv \mathrm{KE}+\mathrm{APE}$, is called the pseudoenergy. When considering the impact of NLIWs on shelf mixing, the physically relevant quantity is the pseudoenergy and not simply the combination of KE and the potential energy, PE.

Conservation laws governing the pseudoenergy have been described in multiple papers (Shepherd, 1993; Winters et al., 1995; Scotti et al., 2006; Lamb, 2007). Though expressions vary slightly depending on the assumptions and generalizations of a particular derivation, the primary difficulty emerges in the designation of the reference density, $\bar{\rho}$. The ocean's density field is neither at-rest nor steady; it is highly variable in both time and space at a multitude of scales. While Shepherd (1993) discusses the possibility of using a Hamiltonian

Published by Copernicus Publications on behalf of the European Geosciences Union and the American Geophysical Union. 
description to deal with inhomogeneous background conditions, accounting for the non-steady nature of the ocean is a daunting problem, particularly when dealing with the limited resolution of observational systems. The fundamental difficulties in adequately resolving the ocean's state at scales relevant to NLIWs make defining $\bar{\rho}$ in this open environment inconclusive at best. To side-step this difficulty, reasonable approximations to the reference density are regularly employed.

For example, Hebert (1998) approximated the reference state of a sampled region by first artificially extending the length of the domain before adiabatically resorting the density. Alternatively, Scotti et al. (2006) reconstructed an averaged background state that varied temporally and spatially using a combination of mooring and shipboard data. Some studies have neglected this difficulty entirely by assuming that the APE and energy flux are reasonably approximated by $\frac{1}{2}\left(g^{2} \rho^{\prime 2}\right) /\left(\rho_{0} N^{2}\right)$ and $\overline{u^{\prime} p^{\prime}}$, respectively, where the prime denotes perturbation fields (usually calculated by filtering) and $N$ is the buoyancy frequency (Brickman and Loder, 1993; Nash et al., 2005; Chang et al., 2006). Although for small amplitude waves these expressions are reasonable, they are not appropriate for larger amplitude waves where the advection of energy contributes significantly to the flux (Scotti et al., 2006; Moum et al., 2007a; Lamb, 2007). For large amplitude waves, like those summarized here, the total flux is the sum, $u^{\prime}\left(E_{\mathrm{k}}+E_{\mathrm{a}}+p^{\prime}\right)$, where $E_{\mathrm{a}}$ is the available potential energy density,

$E_{\mathrm{a}}=g \int_{\bar{\rho}(z)}^{\rho} z-z^{*}(s) d s$.

Here, $z^{*}(s)$ satisfies $\bar{\rho}\left(z^{*}(s)\right)=s$ for a reference density, $\bar{\rho}(z)$, that is monotonic and stable. The reader is referred to Shepherd (1993), Scotti et al. (2006), Lamb (2007), and Lamb and Nguyen (2009) for details of the derivation of $E_{\mathrm{a}}$.

The divergence of the pseudoenergy flux over a measured distance gives an upper bound to the amount of turbulent mixing that occurs in a region. This estimate provides an average quantity, and does not account for the "patchiness" (both vertical and horizontal) of turbulent kinetic energy (TKE) dissipation observed in NLIWs. For example, Moum et al. (2003) document rapid energy loss to turbulent mixing initiated by the onset of shear instabilities, which are typically localized at the back of the wave near the pycnocline. In contrast, Inall et al. (2000) show that for waves observed on the Malin Shelf, TKE dissipation primarily occurs in the bottom boundary layer.

This paper examines pseudoenergy and TKE dissipation in NLIWs observed over the New Jersey shelf. We first begin by introducing the experimental setup in Sect. 2, and follow by detailing the method used to calculate energies from shipboard and mooring platforms in Sect. 3. General observations are presented in Sect. 4, and the temporal and spatial trends are discussed in Sect. 5. Section 6 examines two specific examples of energy exchange: wave interactions and a wave impinging on a topographic bump. The results are summarized in Sect. 7. Note that in the remainder of this manuscript we use the word energy as synonymous with pseudoenergy; in all cases, we are considering the sum of $\mathrm{KE}+\mathrm{APE}$.

\section{Experimental details}

In August 2006, a wave-tracking experiment was conducted over the New Jersey shelf from the R/V Oceanus. Shipboard observations were obtained through 27 distinct NLIW packets at various locations across the shelf. Some packets were comprehensively measured, using both our microstructure profiler, Chameleon (Moum et al., 1995), and shipboard acoustics $(300 \mathrm{kHz}$ and $1200 \mathrm{kHz}$ acoustic Doppler profilers and a $120 \mathrm{kHz}$ echosounder). The Chameleon profiler samples temperature, salinity, pressure, temperature variance, velocity shear, fluorescence, and optical backscatter. From this data, density and turbulent kinetic energy dissipation can be estimated. (The latter quantity is calculated by integrating the shear spectra; details of this process can be found in Moum et al., 1995.) Other wave packets were measured using only acoustics; thus, velocity data are available for these waves but not density or turbulence data.

During profiling, the ship was positioned ahead of a packet and held relatively stationary. Before arrival of the wave packet, "background" profiles were obtained to the full ocean depth. Upon arrival of the waves at the ship, profiles were terminated at roughly $40-\mathrm{m}$ depth, so that the horizontal resolution could be maximized. (That is, the time between profiles was minimized.) The first few NLIWs of a packet were profiled through as the waves propagated past the ship. The profiler was then recovered, and the ship repositioned ahead of the packet. Using visual sightings and X-band radar images, the ship track was maintained roughly perpendicular to wave fronts. In this fashion, packets were tracked large distances (as much as $\sim 50 \mathrm{~km}$ ) across the shelf, although this was not always the case and depending on circumstances some wave groups were measured at only a few stations. The ship-tracked wave groups were named for bookkeeping purposes; names are used here when referring to specific packets.

During wave tracking, vertical profiling time-series were usually obtained through the first three waves before turning the ship and repositioning ahead of the wave group. However, we remained flexible as to the exact number of waves that were profiled through, sometimes capturing only the lead wave while at other times profiling through as many as 10 waves. The technique was modified to adapt to the character of the wave group and our interest at the time; for example, if the wave group appeared to be evolving rapidly, microstructure measurements were obtained only through the first $1-2$ waves so that the ship could be repositioned as quickly as possible. On the other hand, if profiling occurred near an environmental mooring (see below) the series was 
often extended to allow for detailed comparison of mooring and shipboard data. On average, the time interval between profiling periods of a particular wave group was on the order of an hour, corresponding to a horizontal distance of less than $5 \mathrm{~km}$.

This endeavor was part of the larger, multi-institutional NonLinear Internal Wave Initiative and Shallow Water 2006 (SW06) experiment (Tang et al., 2007) funded by the Office of Naval Research, for which an along- and cross-shelf array of environmental and acoustic moorings were deployed (Fig. 1). Most environmental moorings provided either velocity measurements, or well-resolved measurements of temperature with sparser salinity measurements. For the calculation of $E$, we selected moorings that were equipped to measure water column velocity and in a location where NLIWs occurred (i.e., inshore of the 80-m isobath). Three crossshore moorings, SW30, SW37, and SW29, met these requirements (blue diamonds in Fig. 1). Depending on location, shelf moorings recorded the passage of $O(100)$ different wave packets. A more detailed description of the environmental mooring setup is provided in Shroyer et al. (2010b). The cross-shelf coordinate system used in the majority of figures presented here is defined in Fig. 1; note the $0 \mathrm{~km}$ mark is located at the intersection of the mooring array roughly $20 \mathrm{~km}$ inshore of the shelf break.

Ship transects extended more than $20 \mathrm{~km}$ farther inshore than the mooring array (grey cloud, Fig. 1). Although the resolution provided by the ship allowed for the shoaling evolution of waves to be captured; only the first few waves in each group were resolved. In addition, after a wave was followed inshore, we frequently elected to pass by developed wave packets on the return to the shelf break in favor of trying to capture a new wave group at an earlier stage of evolution. Mooring records complimented this perspective by providing localized information about the entire wave field, including the complete structure of individual wave packets. Accordingly the energy analysis of mooring and ship records differ.

\section{Details of energy calculation}

\subsection{Shipboard calculation}

The data collected during semi-stationary times of wave profiling were used to compute wave energy. Time series were converted into spatial series using the observed wave speed, $c$, measured by differencing wave position as a function of time. Wave velocities were estimated by subtracting estimates of background velocity, $u_{0}(z)$, along isopycnals. We defined $u_{0}(z)$ using a $5-10 \mathrm{~min}$ time average of velocity ahead of the wave train. The exact number varied depending on the duration of time that a ship was positioned at a station before arrival of the first wave. Background velocity varied greatly; however, in most cases the magnitude was small compared to the particle velocity of the waves (maxi-

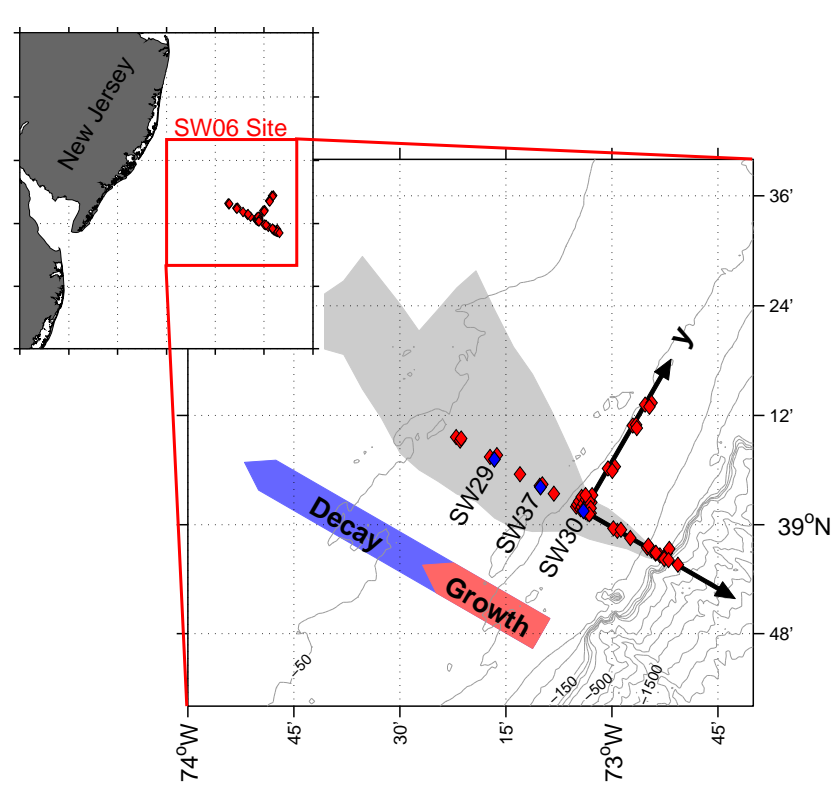

Fig. 1. Site bathymetry, mooring locations (red diamonds) and ship-based transect boundary (grey cloud). Blue diamonds show the cross-shelf environmental moorings that were used to compute NLIW energy. The coordinate system is defined by black arrows with the along-shore direction rotated $30^{\circ}$ clockwise of north. Bold colored arrows estimate regions of wave growth and decay.

mum magnitudes of $0.1-0.2 \mathrm{~m} \mathrm{~s}^{-1}$ compared to greater than $0.5-0.7 \mathrm{~m} \mathrm{~s}^{-1}$ in waves). However, particularly in shallow water, the background velocity was sometimes of the same magnitude as the wave particle velocity. In general, $u_{0}(z)$ contained both a baroclinic and barotropic component. The exact structure is not detailed here simply because of the variability that existed, i.e., at any given location and time the structure could be completely different. (The reader is referred to to Shroyer et al., 2009, 2010a for specific examples of $u_{0}$ observed during the SW06 experiment.) After defining $u_{0}$, the wave kinetic energy was then straightforward to calculate using Eq. (1).

The available potential energy was determined following Lamb (2007) by integrating $E_{\mathrm{a}}$ (Eq. 3) over the wave domain. The reference density was calculated as follows. Although the vertical resolution of density and TKE dissipation was well-resolved (1-m bin averages) through profiling, the horizontal resolution was coarse with approximately 5 profiles through a wave. Interpolation of density between profiles was accomplished using acoustic backscatter from the $120 \mathrm{kHz}$ echosounder. The shelf density structure during the experiment was approximately two-layer, with a sharp pycnocline that typically provided a consistent, strong backscatter return surface. This backscatter surface was used to define the horizontal amplitude structure of the wave, $R(x)$. The vertical structure, $\phi(z)$, of the wave was obtained by using the observed density to calculate the displacement structure function. Thus we assume the displacement is 
separable $(\eta(x, z)=R(x) \phi(z))$; however, we make no assumptions about the analytical form of $R(x)$ and $\phi(z)$. The density field was then calculated as $\rho(x, z)=\rho_{u}(z-\eta(x, z))$, where $\rho_{u}(z)$ is the average density profile measured ahead of the waves. This idealized density field was then used to estimate the "local" reference state, $\bar{\rho}$, at each profiling station. First, the domain size was increased by a factor of 10 using the density structure ahead of the wave; the extended domain was then resorted to define $\bar{\rho}$ (Winters et al., 1995).

Interior wave TKE dissipation, $\epsilon$, was measured directly from shear probes. Values presented here represent averages through the wave cores; data within $10 \mathrm{~m}$ of the surface are neglected due to possible contamination by the ship's wake. Dissipative loss attributed to the waves in the interior of the fluid, was estimated by

$D_{\text {int. }}=\rho_{0} \int_{x_{1}}^{x_{2}} \int_{-z_{\mathrm{L}}(x)}^{0}<\epsilon>-<\epsilon_{0}>d z d x$,

where $z_{\mathrm{L}}$ is the depth of maximum stratification $\left(\max \{N(z)\}=N\left(-z_{\mathrm{L}}\right)\right)$, and the horizontal integration limits extend across the wave. If, at a given location, it was apparent that wave dissipation extended beneath $z_{\mathrm{L}}(x)$, the lower limit was adjusted accordingly (typically less than $5 \mathrm{~m}$ ). The lower integration limit was set in an attempt to standardize the calculation, since individual profile depths were not uniform. Rather than setting a constant depth, this measure was adopted to account for wave perturbations, i.e., this method essentially selects for an isopycnal surface. Note that in general, the fluid was approximately two-layer with the maximum of $N \sim 10^{-1} \mathrm{~s}^{-1}$ across the shelf; accordingly, the integral essentially selects for the upper layer. In reality, the results are not sensitive to the exact limit, since large values of $\epsilon$ are encompassed by the vertical integral and only small values are excluded. $\langle\epsilon\rangle$ is the average of the measured dissipation within the limits of integration, and $<\epsilon_{0}>$ is the average of the measured dissipation within the same vertical limits but in profiles made prior to wave arrival. When $\left\langle\epsilon>\right.$ was less than $\left\langle\epsilon_{0}\right\rangle$ (i.e., dissipation outside the wave exceeded that inside the wave), $D_{\text {int. }}$ was set to zero.

In order to maximize the horizontal resolution of measurements, full water column profiles were only made ahead of waves; during wave passage, profiling was confined between the surface and 40-m depth. Wave profiles extended into the bottom boundary layer only in regions where the water column depth was close to $40 \mathrm{~m}$. We therefore adopted a quadratic drag law to estimate the bottom stress, $\tau=C_{\mathrm{D}} \rho u_{10}^{2}$, using the wave velocity $10 \mathrm{~m}$ above the bottom $\left(u_{10}\right)$. A total of 30 profiling series, which contained measurements into the bottom boundary layer, were used to estimate a drag coefficient of $C_{\mathrm{D}}=0.002$. The relation, $\epsilon_{\mathrm{bbl}}=u_{*}^{3}(\kappa z)^{-1}$, was used to calculate dissipation in the bottom boundary layer, where $\kappa=0.4$ and $u_{*}=\sqrt{\tau / \rho}$. The dissipative loss in the bottom boundary layer was then calculated by

$D_{\mathrm{bbl}}=\rho_{0} \int_{x_{1}}^{x_{2}} \int_{-H}^{-H+10} \epsilon_{\mathrm{bbl}} d z d x$.

In contrast to Eq. (4), $\epsilon_{\mathrm{bbl}}$ is not averaged in Eq. (5) since the horizontal resolution of $\epsilon_{\mathrm{bbl}}$ is set by the ADCP and not vertical profiling. The integral was arbitrarily cut-off at $10 \mathrm{~m}$ above the bottom, but this has little influence on $D_{\text {bbl }}$ because $\epsilon_{\mathrm{bbl}}$ decays as $z^{-1}$ so it is dominated by the near-bed dissipa-

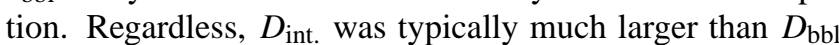
with a median value of $D_{\text {int. }} / D_{b b l}$ of 10 . The total dissipative loss in the waves was calculated as $D=D_{\text {int. }}+D_{\text {bbl }}$.

\subsection{Mooring calculation}

In contrast to ship-tracked waves, for which the wave speed was directly calculated, the wave speed at moorings was estimated by assuming a $\mathrm{KdV}$ correction ( $-10 \mathrm{~m}$ amplitude) to the linear phase speed. This value was used to convert mooring time series into spatial series. SW29, SW30, and SW37 were each equipped with acoustic Doppler profilers (ADCPs), and estimates of KE were made using Eq. (1). Wave velocities were isolated by subtracting a background velocity profile, defined as the 10-min average prior to wave arrival, along isopycnals. Due to surface interference, the upper $\sim 10 \mathrm{~m}$ was not resolved by the ADCPs, and a constant horizontal velocity was assumed for near-surface extrapolation. Vertical velocity was extrapolated linearly to zero at the surface. For mode-1 depression waves maximum horizontal velocities occur at the surface, and we expect this method will bias KE estimates low.

Available potential energy was only directly calculated at mooring SW30, as this was the only mooring where a wellresolved density structure could be calculated. The uppermost density measurement was recorded at $14 \mathrm{~m}$ below the surface; data at the surface was set using the shipboard flowthrough instrumentation. All data recorded within $\pm 8 \mathrm{~km}$ of SW30 was averaged into half-day bins; missing data values were interpolated linearly. The half-day bin average that encompassed the start time of the leading wave was then used as the surface density. In the vertical, density was extrapolated linearly between sensors and to this surface value. SW29 and SW37 were not heavily instrumented with CTD sensors ( $\leq 3$ conductivity sensors); hence, calculation of APE would require extensive interpolation and extrapolation of the density field. Instead, at these moorings, the total energy is estimated using $\mathrm{APE} \approx \mathrm{KE}$. For this experiment, this relationship was tested using shipboard data across the shelf and found to be robust (Sect. 4). After exhausting multiple extrapolation and interpolation techniques for the unknown density field, we concluded that simply using this approximation provided reasonable and the most straight-forward estimates of total energy. 

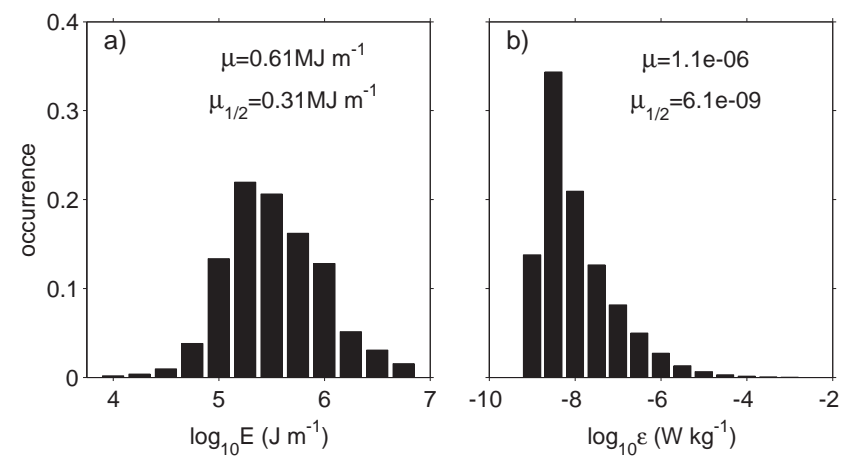

Fig. 2. The frequency distribution of (a) wave energy and (b) dissipation in waves between $10-40 \mathrm{~m}$ depth. The means, $\mu$, and medians, $\mu_{1 / 2}$, are given; distributions are calculated from shipboard data.

A short-coming of the experimental set-up (shipboard observations as well as a primarily cross-shelf environmental mooring array) is that a 2-D wave structure is assumed when computing wave energetics. An along-shelf branch of the mooring array, located along the $80-\mathrm{m}$ isobath, suggests that this assumption is limited, as wave energies were at times roughly an order of magnitude smaller just $10 \mathrm{~km}$ farther up coast (toward the northeast) than at SW30. (At other times, wave energies were similar between the two moorings.) Regardless, we proceed to present the 2-D energy balance, but emphasize that more work is needed to understand the fully 3-D wave field.

\section{Ship-based observations}

In this region, the waves are believed to be formed as a consequence of tidal interaction with the shelfbreak (Shroyer et al., 2010b; Nash et al., 2010). The high-frequency NLIWs were typically first observed roughly $10-15 \mathrm{~km}$ inshore of the shelfbreak and then were tracked by the ship as they propagated inshore. The energy and dissipative loss were calculated for each wave that was profiled through from the ship at each position and time, totaling just over 500 wave "realizations". Below, the general characteristics and statistics of these ship-observed waves are summarized.

\subsection{Energy}

Distributions of ship-observed $E$ are shown in Fig. 2a. The average $E$ was $0.6 \mathrm{MJ} \mathrm{m}^{-1}$, and observed values spanned three decades from $2 \times 10^{4} \mathrm{~J} \mathrm{~m}^{-1}$ to $7 \times 10^{6} \mathrm{~J} \mathrm{~m}^{-1}$. The median value was one-half the mean at $0.3 \mathrm{MJ} \mathrm{m}^{-1}$. In general, KE was approximately equal to APE (Fig. 3). The ratio of KE to APE varied from 0.27 to 3.6 for individual waves (Fig. 3b). This spread may partially be attributed to error associated with extrapolation, interpolation and estimation of $\bar{\rho}$ (see discussion below). The ten-kilometer bin average,
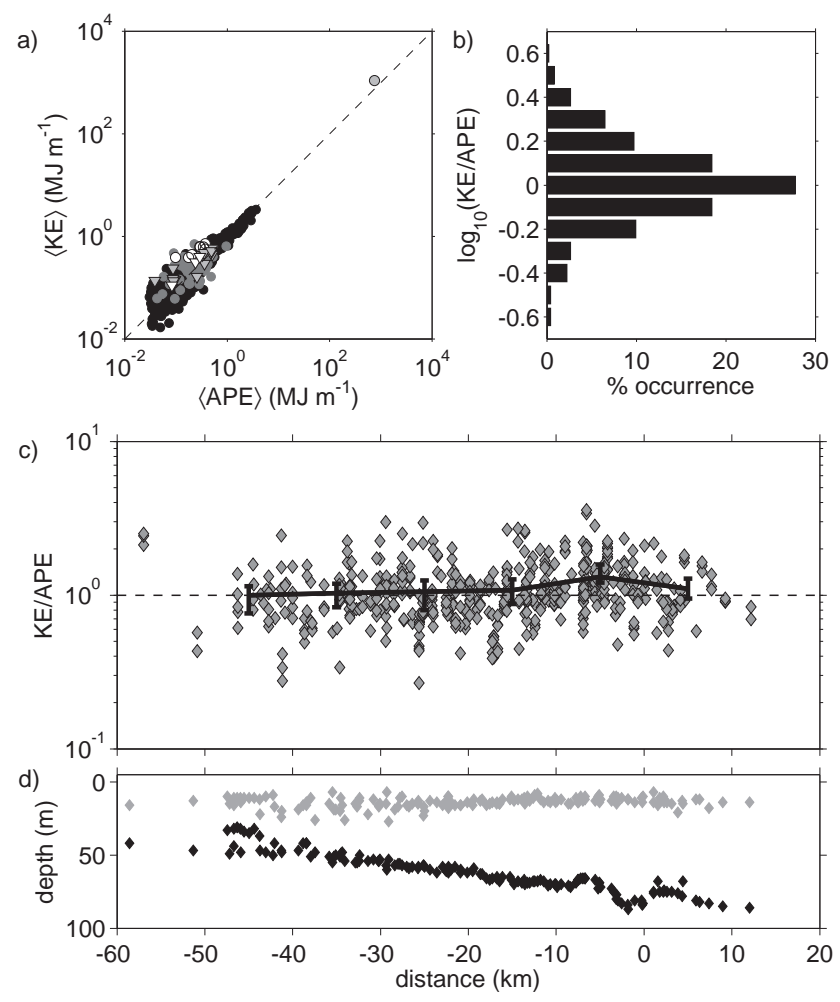

Fig. 3. (a) Ratio of KE and APE for the current study (black dots), as well as several other experiments: open diamonds (Klymak and Moum, 2003), grey diamonds (Moum et al., 2007a), open circles (Moum et al., 2007b), light grey circle (Klymak et al., 2006), and dark grey dots (Scotti et al., 2006). Data are from a variety of locations and include both elevation and depression waves. (b) Histogram of $\log _{10}$ (KE/APE) for waves observed during this experiment. (c) Ratio of KE to APE as a function of cross-shelf distance for the NJ shelf waves. The black line is the $10 \mathrm{~km}$-bin average with error bars showing one standard deviation from the mean ratio. (d) Depth of maximum stratification (grey) and bottom (black) for each profiling series.

which helps to minimize random error, shows little range in this ratio with an offshore value of 1.1 and an inshore value of 1.0 (Fig. 3c). Inshore there are more occurrences of $\mathrm{APE}>\mathrm{KE}$ on a point-by-point basis and even this highlyaveraged value of KE:APE begins to depart from fully nonlinear theory, which requires $\mathrm{KE}>\mathrm{APE}$ (Turkington et al., 1991).

Application of this theory, which neglects dissipation and assumes 2-D waves, is questionable as a wave begins to shoal in a dynamic coastal environment. Recent numerical experiments by Lamb and Nguyen (2009) verify the departure from the relation $\mathrm{KE}>\mathrm{APE}$ for shoaling waves, and a similar trend was noted by Scotti et al. (2006) in Massachusetts Bay, where estimates of the average available potential energy density exceeded the average kinetic energy density at an inshore mooring. The water depth and depth of maximum stratification are shown in Fig. 3d; as the bottom depth shoals, 

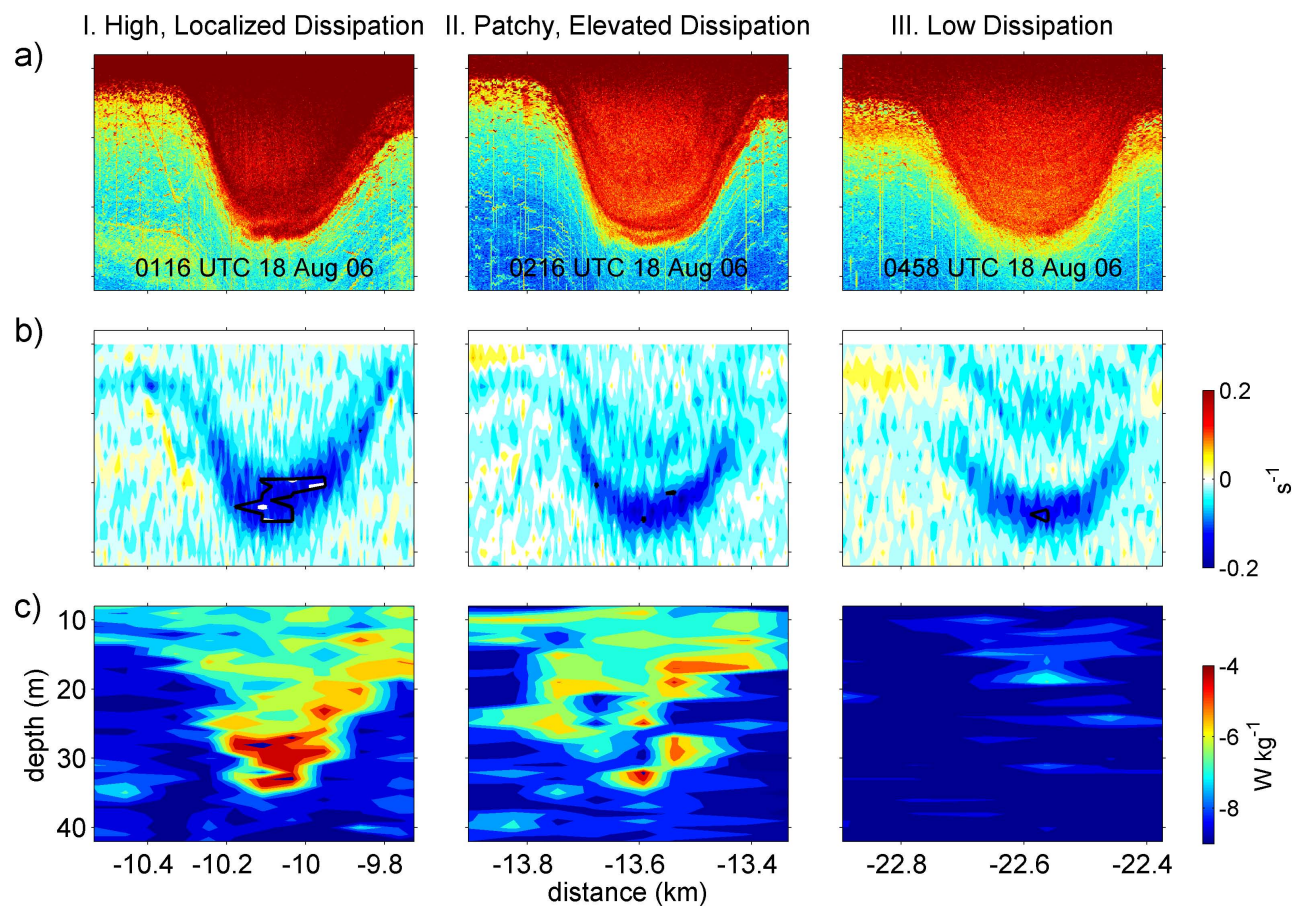

Fig. 4. (a) Acoustic backscatter, (b) vertical shear, and (c) $\log \epsilon$ for the leading wave of one packet (Rosey) at three different times/locations. Contoured in white (black) in panel b) are $R i=\frac{1}{4}\left(R i=\frac{1}{2}\right.$ ) for regions where $N^{2} \geq 2.5 \times 10^{-3} s^{-2}$. This cut-off in stratification was selected so that only values within the pycnocline, where both $N^{2}$ and $u_{z}^{2}$ are large, are plotted.

the pycnocline deepened slightly. The pycnocline does not reach mid-depth; however, the trend is at least consistent with KE:APE $\rightarrow 1$ as the pycnocline approaches mid-depth, as predicted by Lamb and Nguyen (2009).

Although variability is present, the relationship $\mathrm{KE} \approx \mathrm{APE}$ seems to exist in multiple geographic regions for both depression and elevation waves (Fig. 3a). Accordingly, equipartition of energy may serve as a reasonable approximation if only one component is known. While equipartition violates the relation $\mathrm{KE}>\mathrm{APE}$, we argue that the approximation may be useful in estimating total $E$ in the ocean for the following reasons. First, the necessary, well-resolved measurements in both the time and space domain are difficult to acquire; even under the best of circumstances, data extrapolation and interpolation is required. Second, as discussed previously, defining the reference density from limited measurements in an open environment is problematic. The combination of these two factors make error estimates of calculated energy difficult to quantify. To attain some measure of the error associated with sampling resolution, we created KdV solitons for several of the observed background states. "True" $E$ was estimated from complete soliton fields. Solitons were then sampled in a manner consistent with ship-based observations, and $E$ was re-calculated. Resultant estimates indicate that reasonable errors are typically around $25 \%$, a value which in many cases could easily distort the true ratio between KE and APE. Note that this error does not account for uncertainty in $\bar{\rho}$.

\subsection{Dissipative losses}

The distribution of $\epsilon$ (Fig. 2b) was based on all measurements made in the range 10- to 40-m depth, which typically encompassed the pycnocline both inside and outside of wave perturbations. The mean value of $\epsilon$ in the waves was $10^{-6} \mathrm{~W} \mathrm{~kg}^{-1}$; localized values exceeded $10^{-4} \mathrm{~W} \mathrm{~kg}^{-1}$. The median, $\mu_{1 / 2}(\epsilon)$, was $6 \times 10^{-9} \mathrm{~W} \mathrm{~kg}^{-1}$, three orders of magnitude smaller than the mean. This spread between the mean and the median is a result of the "patchiness" of turbulent regions. The qualitative character of wave mixing can be classed into three general categories: I. high, localized dissipation, II. patchy, elevated dissipation, and III. low dissipation (examples shown in Fig. 4).

In the Category I wave state, observations of high dissipation were confined to the trailing edge of waves and coincided with low Richardson number, $R i=N^{2} / u_{\mathrm{z}}^{2}$ (where $N$ is the buoyancy frequency and $u_{\mathrm{z}}$ is the vertical shear). These qualities along with billow-like structures apparent in some backscatter images point to turbulence generated from shear instabilities (Moum et al., 2003). Waves in the Category I state were typically of larger amplitude (roughly -10 -m displacements compared to an average observed amplitude displacement of $-8 \mathrm{~m}$ ); the highest dissipation rates $\left(>10^{-4} \mathrm{~W} \mathrm{~kg}^{-1}\right)$ were observed in this category. Waves in the Category II state displayed elevated dissipation that was distributed throughout the wave core, in regions of high and low shear. This type of observation was the most common, 
and while dissipation was elevated from background levels, values were not typically as large as those observed in the first category. The third category is comprised of waves with very low dissipation or waves with $D_{\text {int. }}=0$, i.e., the interior background dissipation exceeded wave dissipation. Category III states occurred in waves of both large and small amplitude.

The examples shown in Fig. 4 were selected not only because the series illustrates these three categories, but also because it emphasizes that the character of mixing was not directly related to amplitude. Furthermore, as should be expected, the series highlights the rapid evolution of turbulent regions in time and space in that transects were obtained from the same leading wave within wave group Rosey and were separated by only a few hours (kilometers). The illustration is also useful because it suggests a possible dynamical reason of the character difference in waves, with the onset of shear instability associated with low Richardson number (Category I), the energy cascade to smaller scales (Category II), and the eventual damping of TKE dissipation (Category III).

\section{Spatial and temporal trends in NLIW energetics}

The variability in the NLIW field on the New Jersey shelf was manifested over a variety of temporal and spatial scales. In this section, long-term (large-scale) trends are documented; and short-term, rapidly evolving changes in energetics are discussed in the following section. Here, we only briefly note temporal trends in NLIW energy, as the variability of the internal tide, and its consequent effect on the NLIWs, are the subject of a separate manuscript (Nash et al., 2010). More detail is given to the spatial evolution of waves.

\subsection{Temporal variability}

The observed wave energies varied considerably in time, with larger amplitude, more energetic waves occurring between 16-22 August 2006 (Fig. 5). Mooring time series, which have the advantage of resolving all NLIWs at one location, are used to highlight temporal variability (Fig. 5a), although shipboard data show the same change (Fig. 5b). NLIW energies during this 7-day period were roughly an order of magnitude larger than at other times during the experiment. This time period was not related to the barotropic spring tidal cycle (Fig. 5c), but instead corresponded to a time of increased shoreward, internal energy flux. This period also coincided with the onset of upwelling winds and a shift in mesoscale stratification at the shelf break (Shroyer et al., 2010b). This shift in character of the NLIWs is thought to be related to the relationship between the locally- and remotely-generated internal tide at the shelfbreak, and the topic is the focus of ongoing work (Nash et al., 2010).

The difference in turbulent mixing between the time periods of large and small waves is quantified in Fig. 6a. The average $\epsilon$ was $55 \%$ greater during the period of large ampli-
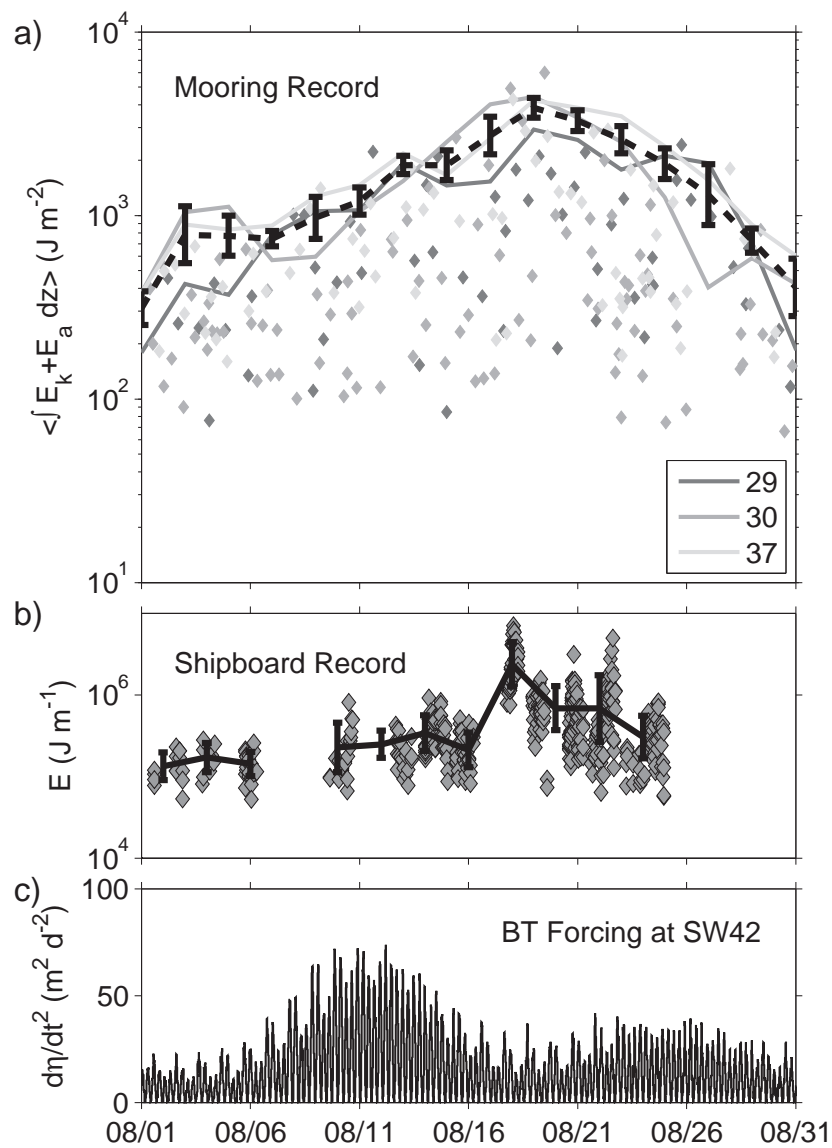

Fig. 5. (a) Daily average (solid lines) of the depth-integrated NLIW energy calculated at three cross-shelf moorings. Diamonds represent individual wave estimates; the bold, dashed line is the daily mean averaged over the three moorings with $95 \%$ boot-strapped confidence limits. (b) Shipboard estimates of total wave energy. Diamonds show values for individual waves, and the bold line is the 2-day bin average with error bars spanning one standard deviation. (c) Barotropic forcing at the shelf break.

tude waves, and the average turbulent diffusivity, $K_{\rho}$, was $70 \%$ greater over this same time period (Fig. 6b). $K_{\rho}$ was calculated using

$K_{\rho} \equiv \frac{\Gamma \epsilon}{N^{2}}$,

where $\Gamma=0.2$ is the mixing efficiency (Osborn, 1980). Thus, turbulent mixing is roughly a factor of two larger between the two time periods, whereas energies differed by a factor of ten.

\subsection{An evaluation of cross-shelf evolution}

While shipboard observations do not capture the entire wave train, the data set allows for the cross-shelf evolution of wave energetics to be studied. For this analysis, we evaluate the total energy in the leading three waves of each group; and, all 

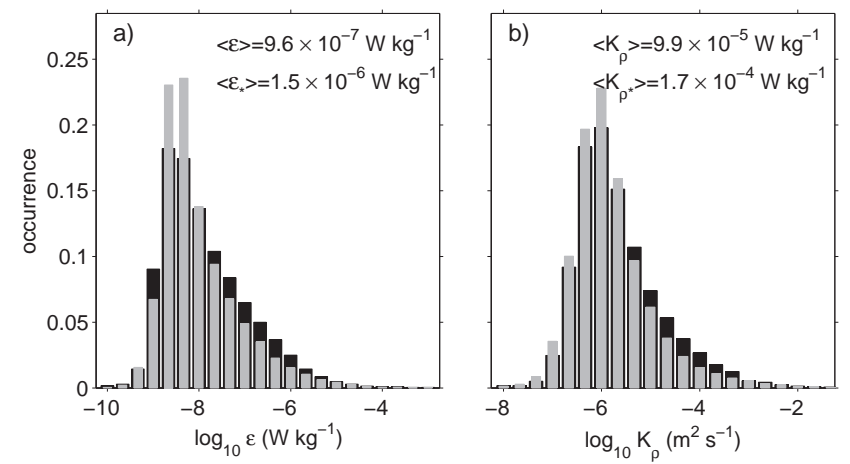

Fig. 6. Histogram of (a) $\epsilon$ and (b) $K_{\rho}$ from $10-40 \mathrm{~m}$. Grey bars correspond to waves observed prior to 16 August 2006 and black bars show values for waves observed between 16-24 August 2006. Average values for the first time period are approximately $40 \%$ of those in the second time period (denoted with a subscript star).

references to energies and dissipative loss in the remainder of this section are integrated over the leading three waves. This number was selected because i) integrating over several waves "filters" the short term changes discussed in Sect. 6 and ii) in most cases (85\%) this was the minimum number of waves profiled through before the ship was re-positioned. If, at any given location, less than three waves were sampled, the energy was weighted appropriately. (E.g., if only two waves were measured the total energy was multiplied by $3 / 2$ in order to approximate the energy in three waves.) Given the general tendency for the leading wave to be the largest, we recognize that this approximation may be an over-estimate. Waves with a weighting factor of $3 / 2$ make up $9 \%$ of the observations, and waves with a weighting of 3 compose $6 \%$ of the observations.

The cross-shelf evolution of wave energetics is shown in Fig. 7. A clear trend was observed as leading waves initially grew in energy (amplitude) as they propagated onshore; at approximately $20 \mathrm{~km}$ inshore of the T-axis of the mooring array, loss to dissipation (both in the bottom boundary layer and the interior) resulted in wave decay. This figure is composed of 130 data points from 16 of the 27 shiptracked wave packets, leaving 11 omitted wave packets. Five of these 11 groups were tracked using only acoustics, precluding direct measurement of APE and more importantly $\epsilon$, since the former may be estimated using KE. Another four wave groups were profiled through at only one station so that their evolution was not documented. A mode-2 packet (Wave Jasmine), whose energetics are explored by Shroyer et al. (2010a), was also discarded, and the final exception, Isaac, is discussed in Sect. 6.

Figure 7a shows $E$ at each profiling series of the remaining 16 wave packets. Individual profiling sites of the larger amplitude wave groups, which dominate the trend, are connected with thin black lines. Note that the bin average (redblue line) is representative of these individual wave packets. a)

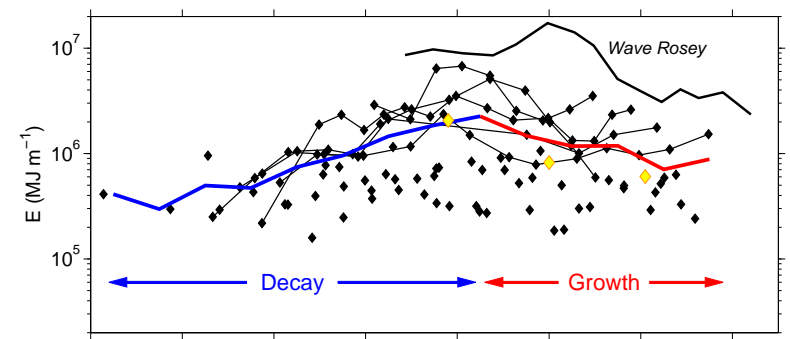

b)

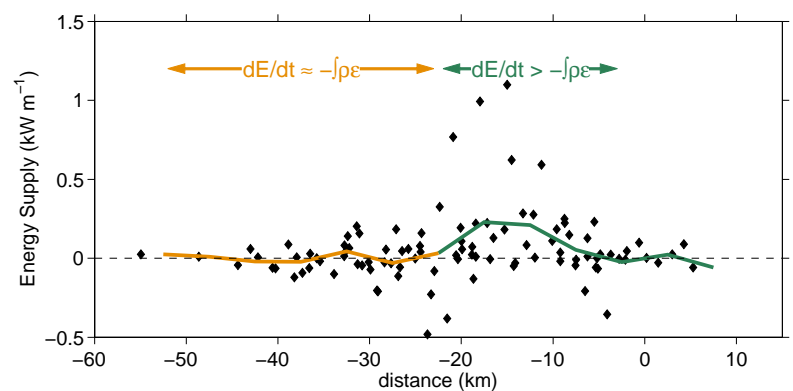

Fig. 7. (a) Black diamonds show the total energy for the leading three waves at each profiling station; individual profiling sites for selected waves are connected with thin black lines. Energies for Wave Rosey are indicated with the thick black line. The thick colored line gives the bin average of energy, excluding Wave Rosey. Mooring-based energies calculated for the ship-tracked wave groups are indicated with yellow diamonds. (b) Black diamonds represent the value $d E / d t+\int \rho \epsilon$. The shaded line shows the bin average.

The difference between the mooring (yellow diamonds) and shipboard mean may be attributed to the extrapolation of velocity data to the surface required for mooring records. Wave Rosey stands out as an anomaly, and is not included in the bin-averaged line or mooring data points. This wave was likely amplitude-limited and is discussed in detail in Shroyer et al. (2010b).

We define the energy supply in the waves as

Energy Supply $=\frac{d E}{d t}+D$.

When this quantity is zero either (i) $E$ does not change and $D$ is negligible, or (ii) decay is balanced by dissipative loss. (Note that by definition $D$ is positive definite.) The energy supply includes terms such as the interaction between the mean flow and the waves, 3-D effects, or any other sources/sinks not accounted for by the dissipative loss. The energy supply for all wave groups (excepting Rosey) is shown in Fig. 7b. As may be expected, the region of energy growth is generally associated with a supply that is greater than zero, i.e., energy is added to the leading three waves. Although termed "supply", the quantity can also be negative. These cases may indeed be real (e.g., when the waves lose energy to the mean), or they may be representative of the inability to accurately account for the total dissipative loss 
based on point measurements of $\epsilon$. Since $d E / d t$ is non-zero over the region of wave decay, the tendency for the energy supply to be near zero indicates a balance between decay and turbulent dissipation, similar to that observed for waves off the Oregon shelf by Moum et al. (2007b). Caution should be exercised when considering individual "points" of energy supply, as this quantity can be largely influenced by localized values of high dissipation. This quantity should in reality be viewed as an average over a larger scale as opposed to an exact balance at a specific point, since the true temporal and spatial extent of mixing events is not known (i.e., observations only provide a snapshot).

\subsubsection{Growth}

The observed growth of the first few waves of a packet may have occurred at the expense of energy from the bore-like component of the internal tide. Here, we use bore-like to refer to the long-term $(\sim$ a few hours) density offset of the internal tide, upon which the higher-frequency NLIWs were sometimes imposed. Nonlinearity prohibits a simple, additive separation of wave and bore energy; and yet, the temperature records at SW30 and SW29 provide evidence of this exchange. Note that $S W 30$ was located at $0 \mathrm{~km}$, slightly inshore of the NLIW formation region and at the beginning of the growth trend (Fig. 7). On the other hand SW29, located at $-21 \mathrm{~km}$, was positioned near the location of "peak" wave energy that occurred just prior to decay. At SW30 isotherms typically maintained a bore-like offset long after the passage of the leading waves, while at SW29 isotherms returned to near rest positions within a relatively short period of time. This trend was noticeable in a majority of the wave packets, and in particular was a robust feature of largeramplitude, ship-tracked waves that dominate the trend presented in Fig. 7a.

To quantify the bore-like nature of the wave trains, displacements were calculated for thermistors located near 20m depth using

$\eta=\frac{T^{\prime}}{\overline{\partial T / \partial z}}$,

where $T^{\prime}$ is the perturbation temperature and $\overline{\partial T / \partial z}$ is the mean temperature gradient centered at $20 \mathrm{~m}$. This depth was selected due to its proximity to the average pycnocline depth, where maximum displacements are expected to occur. Furthermore, sensors above this depth gave unreliable wave displacements due to the (nearly) unstratified surface water. Displacements were calculated at both SW30 and SW29; only those waves that could be reliably tracked between these two moorings were used in this analysis. A crude estimate of the bore displacement was then obtained by taking the minimum displacement over 25-min bins. An example calculation is shown in Fig. 8a for Wave Anya. Solid lines show estimated total displacements, and dashed lines represent the bore component at SW30 (black) and SW29 (grey).
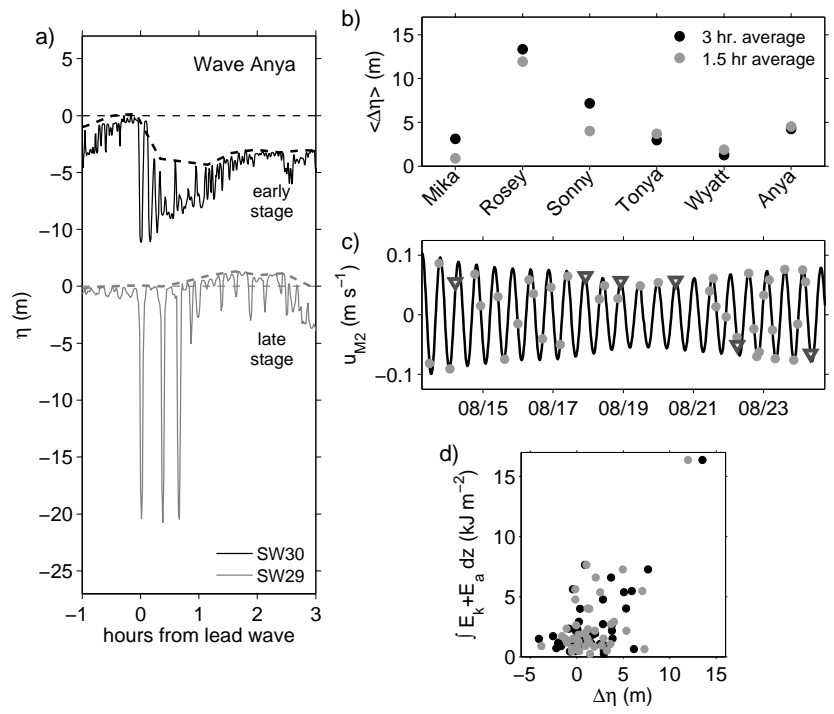

Fig. 8. (a) Displacements at SW30 (black) and SW29 (grey) for Anya. Solid lines show total displacement and the low-frequency bore displacements are dashed lines. (b) Average change in bore displacements between SW29 and SW30 for large amplitude shiptracked waves. Positive $\Delta \eta$ indicates larger displacements at SW30. (c) Wave arrival times at SW30 as compared to the barotropic crossshore M2 velocity at SW40, a shelf-break mooring. All NLIW arrival times measured at SW30 between 13-25 August 2006 are shown, and the 6 ship-tracked waves listed in panel b) are highlighted by dark grey triangles. (d) The maximum depth-integrated energy at SW29 as a function of $\Delta \eta$ for all wave groups (as observed from mooring records) tracked between SW30 and SW29.

A change in the bore displacement between SW30 and SW29 was then calculated by subtracting, $\Delta \eta=<\eta_{29}^{\text {bore }}>$ $-<\eta_{30}^{\text {bore }}>$, so that a positive $\Delta \eta$ indicates a larger bore at SW30. Here the angle brackets denote averages over 1.5 and $3 \mathrm{~h}$. Two time intervals were chosen to ensure robustness of the calculation. Both measures show similar trends, and either may be used for comparison. The results for the largest six, ship-tracked waves are presented in Fig. 8b. In all cases, $\eta_{30}^{\text {bore }}$ exceeded $\eta_{29}^{\text {bore }}$ (i.e., $\Delta \eta>0$ ). Rosey once again stands out as anomaly with $\Delta \eta 2-3$ times larger than that of other ship-tracked waves. Extending the analysis to other NLIW packets recorded in the mooring data shows a general trend in which larger values of $\Delta \eta$ correspond to larger wave energies at SW29 (Fig. 8d).

The energy transfer from the tidal bore to the NLIWs results in amplitude growth of the leading waves and an increase in the number of the waves per packet between SW30 and SW29. This story is not unique and has analogues in many other regions (e.g., Colosi et al., 2001; Ramp et al., 2004; Moum et al., 2007a). The result is consistent with nonlinear steepening and subsequent dispersion of an initially linear internal tide (Holloway et al., 1997; Grimshaw et al., 2004). If this is indeed the case, the distance between SW30 
and SW29 represents an upper-bound on the distance/time required for the dispersion of the internal tide into highfrequency NLIWs. However, this simple picture is complicated by the irregularity of wave arrival times with respect to the barotropic tide (Fig. 8c), which are indicative of the complex nature of the internal tide in this open-shelf environment. Note that even the large amplitude waves listed in Fig. $8 \mathrm{~b}$ do not occur at the same phase of the barotropic tide, with Wyatt and Anya occurring roughly $12 \mathrm{~h}$ out-of-phase with the other waves.

Neglecting Rosey, most of the large amplitude wave packets exhibited a lag between formation and the onset of growth (occurring at roughly $-5 \mathrm{~km}$ ). The delay in wave growth may be attributed to error in energy estimates, unaccounted for interactions between the waves and mean velocity shear, or possibly gradients in cross-shelf stratification. During the observational period there was a general trend for the pycnocline to sharpen inshore, i.e., the fluid became more two-layer like. We also note that onset of growth is consistent with the inshore extent of frontal meanders (personal communication from Glen Gawarkiewicz, Woods Hole Oceanographic Institution, 2010), which exert control on the background stratification through which NLIWs propagated. These circumstances may be coincidental; but, they, along with a quantification of the feedback between the mean velocity and wave energy, deserve further exploration and are the focus of an ongoing effort to understand mesoscale influences on NLIWs.

\subsubsection{Decay}

Waves reached maximum amplitudes/energies at approximately $40 \mathrm{~km}$ inshore of the shelf break $(x=-20 \mathrm{~km})$. Past this location, a general balance between wave decay and dissipative loss was maintained (Fig. 7). Of the 16 waves plotted in Fig. 7, 13 were tracked into the decay regime. (The remaining three groups were small amplitude with the peak energy, $E_{\max }$, summed over the leading three waves equal to $\sim 0.5 \mathrm{MJ} \mathrm{m}^{-1}$ for each group.) The average wave decay, $-d E / d t$, was calculated using a least squares fit to a linear trend over the period of energy loss. As may be expected, based on the general balance between the local energy loss and turbulent dissipation (Fig. 7b), this average measure of decay balances the average dissipative loss (Fig. 9a).

While at a specific time there is not a direct relationship between wave energy and TKE dissipation (Fig. 4), the average decay, and consequently the dissipative loss, scales with $E_{\max }$ (Fig. 9b), so that larger waves lose energy more rapidly than the smaller waves. A similar trend was noted by MacKinnon and Gregg (2003) to the north of the present study site. A simple linear regression of $d E / d t$ on $E_{\max }$ results in a decay rate $\mu=24 \times 10^{-6} \mathrm{~s}^{-1}$ with an $R^{2}=0.88$. Using the average wave speed $\left(0.8 \mathrm{~m} \mathrm{~s}^{-1}\right)$, the decay rate is equivalent to a length scale of about $35 \mathrm{~km}$ and
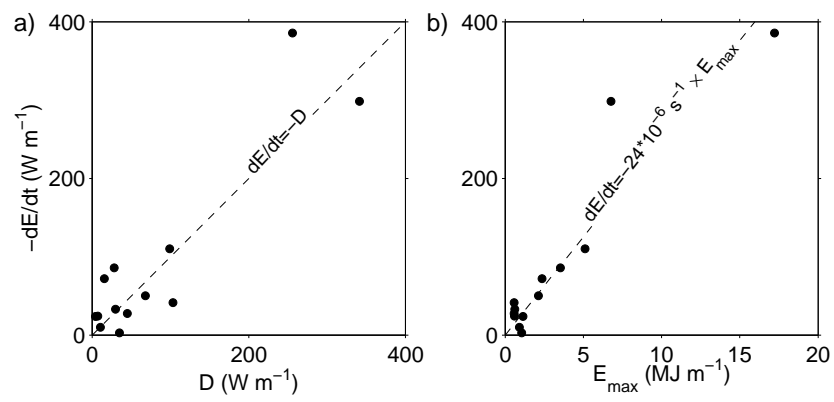

Fig. 9. The average energy loss per unit time compared to (a) the average dissipative loss and (b) maximum $E$ for ship-tracked wave groups that exhibited decay. Each point represents an average over the decay phase of each wave group.

a time scale of $\sim 12 \mathrm{~h}$. Larger waves that typically exhibited larger wave speeds will have longer decay length scales than smaller waves. Since SW29 was located near the region of maximum energy for the ship-tracked waves, we extend this analysis to all NLIWs observed at this mooring. The resultant daily average of the parametrized dissipative loss, $D_{*}=\mu E_{\max }=24 \times 10^{-6} \mathrm{~s}^{-1} E_{\max }$, is shown in Fig. 10, where $E_{\max }$ is approximated as $2 K E$ at $\mathrm{SW} 29$ as discussed in Sect. 3.

This approach is essentially the same as a flux divergence estimate of dissipative loss,

$D_{F_{x}} \equiv \frac{\partial F}{\partial x} \approx \frac{\Delta F}{\Delta x}$,

where at each location, $x$, the flux, $F$, is calculated by integrating $u^{\prime}\left(E_{\mathrm{a}}+E_{\mathrm{k}}+p^{\prime}\right)$ over the water column depth and across the wave train. Writing the energy flux as $F=c E$ (e.g., Moum et al., 2007a), $D_{F_{x}}$ becomes $\Delta(c E) / \Delta x$. If we then consider the distance $L$ over which all NLIW energy is dissipated, the decay rate may be approximated as $\mu \approx c / L$. The relation between $D_{F_{x}}=c E / L$ and $D_{*}=(c / L) E_{\max }$ is then obvious.

Comparison between the daily average $D_{F_{x}}$ and $D_{*}$ at SW29 shows a good agreement between the methods, although peaks evident on 14 and 19 August 2006 in the flux divergence estimate are greater than those estimated by the parameterization (Fig. 10). Note that $D_{F_{x}}$ was calculated using Eq. (9) with $p^{\prime}$ calculated as defined by Moum and Smyth (2006) and assuming that all wave energy was dissipated within $40 \mathrm{~km}$ (established using the inshore bound of wave tracking). The density field, upon which $E_{\mathrm{a}}$ and $p^{\prime}$ depend, was created by mapping "nearby" (in time and space) ship-based profiles onto mooring-derived streamlines. Although $D_{*}$ is not directly applicable to other geographic regions, the decay time and length scales of the waves may provide a useful comparison to NLIWs in other areas. 


\section{Local energetic transformations}

Imposed on the larger scale trends are short (both in time and space) episodes of rapidly evolving wave energetics. Here, we present two examples of short-term energy exchange between NLIWs. The first example details interactions between waves. These events are associated with an observed sudden increase in energy of a leading wave, caused by the constructive interference of two or more individual waves, followed by an extreme drop in energy associated with loss to turbulent production, combined in one case with the "re-separation" of the wave. As a second example, we detail the evolution of one wave group, Isaac, that encountered a small topographic rise. In this case, an abrupt change in topography along with the onset of strong, opposing barotropic currents greatly affected wave structure, energy, and dissipation. In contrast to Sect. 5.2, in Sect. 6.1 energy will be calculated for individual waves, and in Sect. 6.2 energy will be calculated by integrating over a fixed distance.

\subsection{Wave interactions}

The convergent region at the leading edge and the divergent region at the trailing edge of surface-trapped, depression waves modulate the gravity wave field, creating alternating bands of rough and smooth water and providing a means of remotely observing NLIWs. Remote imagery (e.g., Tang et al., 2007, Fig. 2) and shipboard radar images from the SW06 study site often show cusp-shaped interference patterns that are attributed to interactions between wave groups oriented at slightly different angles. Interactions may also occur between waves traveling in the same direction, if a trailing wave is able to overtake those ahead. For example, if a leading wave is of smaller amplitude than a trailing wave, weakly nonlinear (WNL) theory predicts that the waves will re-order by amplitude with the larger amplitude wave traveling faster than the smaller wave. If WNL, the waves will pass through one another without change in form or wave speed; and the only evidence of the interaction is a change in phase of the two waves, i.e., the larger amplitude wave is advanced slightly, while the smaller wave is impeded as the waves exchange position (Drazin, 1984). These data show that turbulent mixing is an important process in the observed interactions; hence, the outcome predicted using WNL theory (which does not account for instabilities in waves) is not expected to hold for the observed large amplitude waves. Here, we present evidence of interactions between multiple wave packets and between waves of the same group.

\subsubsection{Group-group interactions}

The X-band radar imagery (Fig. 11) provides a clear illustration of the intersection of two distinct wave packets. Wave directions (indicated by white arrows) were calculated by computing the average propagation angle over $1 \mathrm{~h}$ from

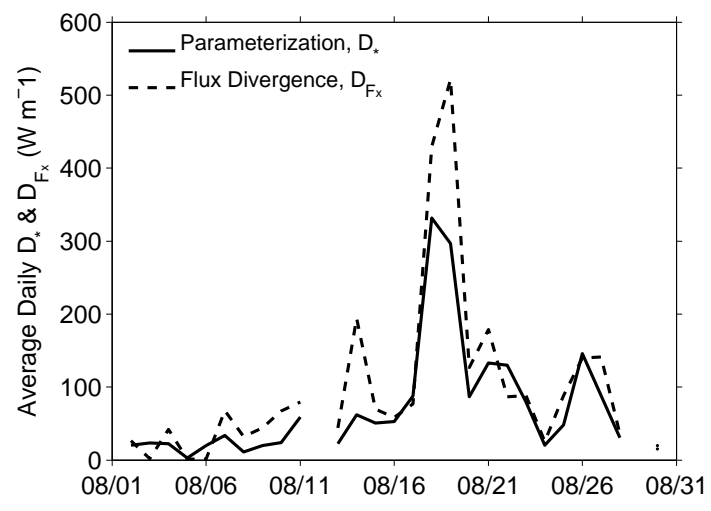

Fig. 10. Estimates of average dissipative loss in the waves as calculated for the scaled fit (solid) and NLIW flux divergence (dashed).

data images (120 images) surrounding the snapshots shown in Fig. 11. Initially the northern packet had a heading of approximately $290^{\circ}$, and the southern packet maintained a heading of about $310^{\circ}$. Around $-20 \mathrm{~km}$ the two packets are difficult to distinguish in the radar imagery and a combined heading of $300^{\circ}$ is estimated for the resultant interference pattern. Unfortunately, past approximately $-30 \mathrm{~km}$ the radar signature of the NLIWs deteriorated rapidly.

During the profiling period near $-10 \mathrm{~km}$, velocity data allow for minimization of the along-wave front velocity component to determine wave orientation. Applying this method to the two lead waves, we find that the first wave propagated with a heading closer to $290^{\circ}$ as compared to the second wave's heading of $300^{\circ}$. While the difference is small, it is clearly distinguishable in the velocity data; however, inshore of this location, computation of a difference in wave orientation using velocity data is ambiguous, which is consistent with radar imagery.

Beneath the surface, acoustic backscatter imagery provides a complimentary perspective of the group interaction (Fig. 12a). In this sequence, the larger amplitude leading wave of the trailing group catches up to the leading wave of the first group, forming a very large amplitude $(\sim-20 \mathrm{~m})$ wave at $-16.5 \mathrm{~km}$. In contrast to weakly-nonlinear theory, which predicts that the waves should pass one another with only a change in relative phase, the observed waves do not continue independently of one another. Perhaps surprisingly, the large amplitude composite wave separates into two waves with the smaller amplitude wave taking the lead. Inshore of $-19 \mathrm{~km}$, these two leading waves were seemingly linked and continued through the shoaling process together (Shroyer et al., 2009).

An analysis of the evolving energetics is consistent with the suggested interaction (Fig. 12c, blue diamonds). The total energy for the lead disturbance of Wave Tonya at $-12.5 \mathrm{~km}$ was $1.5 \mathrm{MJ} \mathrm{m}^{-1}$ (T1), and the total energy in the second wave (T2) at this same location was $1.4 \mathrm{MJ} \mathrm{m}^{-1}$. The combination 


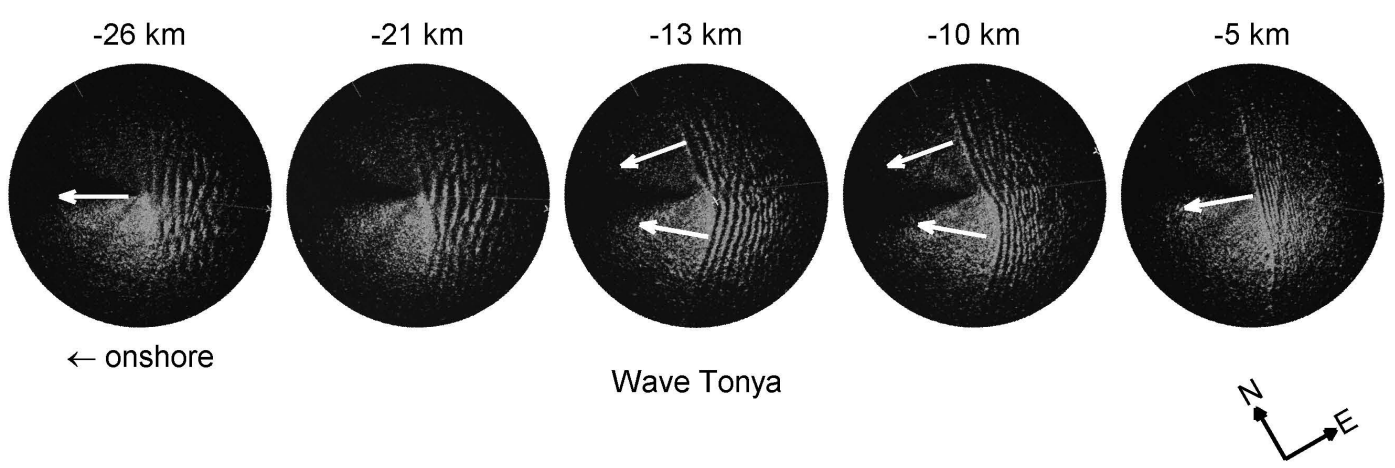

Fig. 11. Group-group interaction as depicted by a series of ship radar images for Wave Tonya. Distances along the wave path are indicated above each figure. Wave vectors calculated from these images are shown in white. The wave group propagated onshore, i.e., from right to left. Radial distance is $5.6 \mathrm{~km}$ (3 nautical miles).

(a)

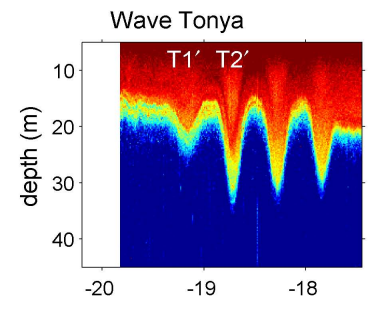

(b)

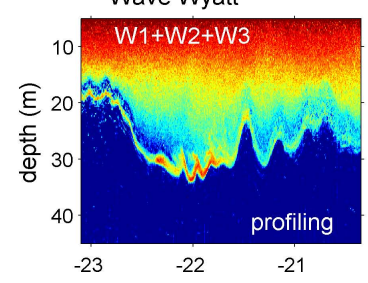

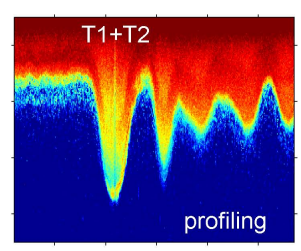
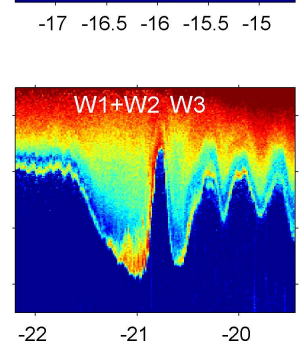
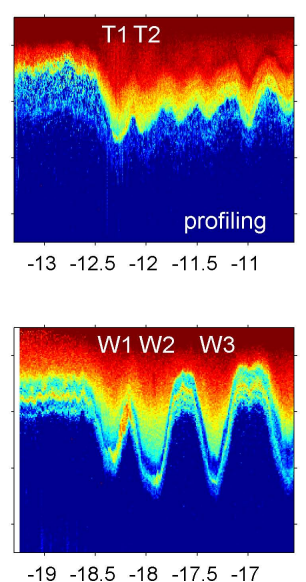
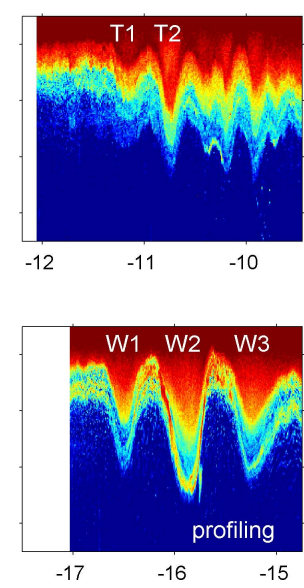

(c)

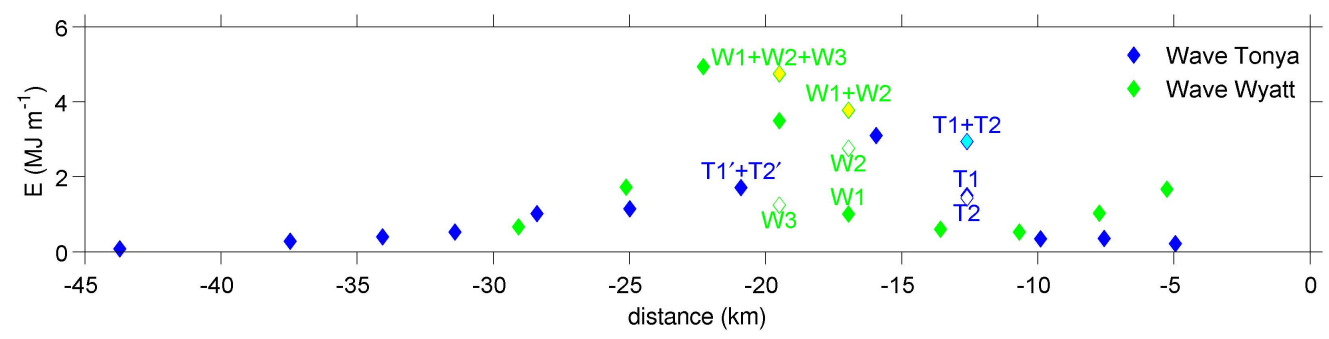

Fig. 12. Sequence of acoustic backscatter transects of (a) Wave Tonya and (b) Wave Wyatt showing the hypothesized interactions. Transects made during ship profiling periods are indicated in lower right of backscatter images; other transects were made as ship steamed through waves in order to re-position ahead of the packet (refer to Sect. 2). (c) $E$ of the leading wave for Tonya (solid blue) and Wyatt (solid green). $E$ in the second waves (open diamonds) and the combined $E$ of the first and second waves (blue/cyan and green/yellow diamonds) are shown at locations just prior to wave interactions. Wave labels are centered either above or below the corresponding markers. Since both Tonya and Wyatt were profiled through at $-16.5 \mathrm{~km}$, at this location markers were shifted offshore/onshore by $0.5 \mathrm{~km}$ for Tonya/Wyatt for visual clarity.

(T1+T2) equal to $2.9 \mathrm{MJ} \mathrm{m}^{-1}$ was approximately the same as the leading (combined) wave energy $\left(3.1 \mathrm{MJ} \mathrm{m}^{-1}\right)$ at $16.5 \mathrm{~km}$. After the intersection, approximately half of the energy $\left(1.7 \mathrm{MJ} \mathrm{m}^{-1}\right)$ was redistributed into two smaller waves (T1' and $\mathrm{T}^{\prime}$ '). The remainder $\left(1.4 \mathrm{MJ} \mathrm{m}^{-1}\right)$ was lost to turbulent dissipation, $D=340 \mathrm{~W} \mathrm{~m}^{-1}$, over $1.2 \mathrm{~h}$.

\subsubsection{Wave-wave interactions}

Backscatter images for Wave Wyatt also show evidence of a wave interaction (Fig. 12b). However, unlike Tonya, neither radar imagery nor velocity data provide any evidence of disparate orientations for the first and second waves that combine to form the large amplitude wave at $-21 \mathrm{~km}$, indicating 
that these two waves were likely part of the same wave group. Modeled NLIW trains are known to establish packets that are rank ordered, larger amplitude waves traveling faster. The amplitude of the second wave (W2) was greater than the first (W1) at $-16.5 \mathrm{~km}$ (Fig. 12b, right panel), indicative of a faster phase speed and possibly allowing the second wave to overtake the first. Using backscatter transects from -16 to $-20 \mathrm{~km}$ a difference in phase speed of $0.07 \mathrm{~m} \mathrm{~s}^{-1}$ was estimated between the second and first wave, assuming that the two waves collided near $-19 \mathrm{~km}$. Calculating the difference in weakly nonlinear phase speed due solely to the different amplitudes of $\mathrm{W} 1$ and $\mathrm{W} 2$ near $-16 \mathrm{~km}$, we find a predicted $\Delta c=0.1 \mathrm{~m} \mathrm{~s}^{-1}$. Analysis of radar imagery in this same range confirms the second wave traveled roughly $0.06 \mathrm{~m} \mathrm{~s}^{-1}$ faster than the first. However, a clear interaction between the waves is not distinguishable using shipboard radar images due to a deterioration in the clarity of the fronts in the backscatter return. The change in the backscatter signal may have been linked to the interaction, which would blur the typical pattern of surface convergence-divergence through the wave train thus affecting the character of the radar return signal.

The sum of the total energy of the first two waves (W1+W2) at $-16.5 \mathrm{~km}$ was $3.8 \mathrm{MJ} \mathrm{m}^{-1}$ (green diamonds, Fig. 12c), which was in agreement with the total energy of the lead wave at $-19.5 \mathrm{~km}\left(3.5 \mathrm{MJ} \mathrm{m}^{-1}\right)$. Continuing this analysis to $-22 \mathrm{~km}$, we find that the sum of the energy of the first two waves at $-19.5 \mathrm{~km}$ was $4.7 \mathrm{MJ} \mathrm{m}^{-1}$; this value agrees with the total $E$ of the lead wave at $-22 \mathrm{~km}$ $\left(4.9 \mathrm{MJ} \mathrm{m}^{-1}\right)$. Hence, we theorize the lead wave at $-22 \mathrm{~km}$ is actually resultant from the combination of the first three waves (W1+W2+W3) near $-16 \mathrm{~km}$ (Fig. 12b). The leading wave at $-22 \mathrm{~km}$ loses almost all of the energy gained during this interaction to intense mixing $\left(>600 \mathrm{~W} \mathrm{~m}^{-1}\right)$; and in contrast to Wave Tonya, the combined wave never re-separated into multiple waves.

The asymmetry in the leading wave at $-21 \mathrm{~km}$ was pronounced; and the rear face was extremely steep, possibly approaching the breaking limit. However, the breaking criterion defined by Vlasenko and Hutter (2002) was not met; hence kinematic instability was unlikely. On the contrary, examination of the Richardson number criterion shows that the severe deformation of the lead wave past this point (onshore panel in Fig. 12b) may have been the result of shear instability. The inverse Richardson number through the lead wave at $-19.5 \mathrm{~km}$ is shown in Fig. 13a, regions greater than 4 that support the development of shear instabilities are contoured in white. The values were calculated using 1-m density and velocity bins. Figure $13 \mathrm{~b}$ emphasizes the extremely large values $\left(>10^{-4} \mathrm{~m}^{2} \mathrm{~s}^{-3}\right)$ of $\epsilon$ observed during this time period. High resolution $(O(\mathrm{~cm}))$ density profiles, reveal the existence of density overturns (Fig. 13c) with an average $\mathrm{L}_{\mathrm{T}} \sim 1.3 \mathrm{~m}$ and maximum $\mathrm{L}_{\mathrm{T}} \sim 2.5 \mathrm{~m}$ through the latter portion of the wave. Note that although the wave shown in Fig. 13 was measured at an early stage of the proposed in-
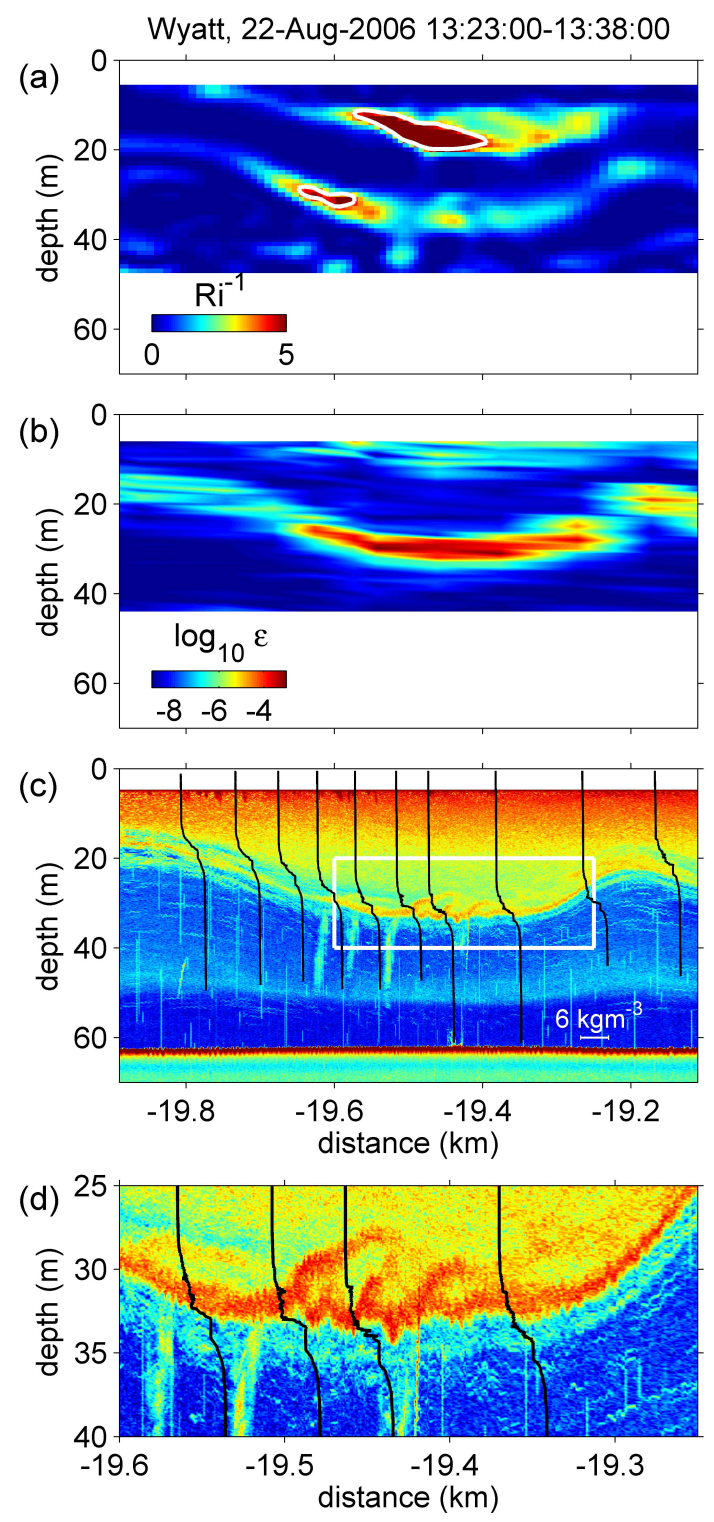

Fig. 13. Structure of Wave Wyatt near maximum amplitude. (a) Inverse Richardson Number $\left(R i^{-1}\right)$. White contours define $R i^{-1}=4$. (b) Turbulent Dissipation $\left(\log _{10} \epsilon\right)$. (c) High resolution density profiles $(O(\mathrm{~cm}))$ are overlaid in black on the the acoustic backscatter image of lead wave. Overturns are evident through the latter portion of the wave. (d) Zoom-in of white box shown in panel c.

teraction, strong mixing and backscatter billows were measured throughout the interaction. We, therefore, suppose that mixing was sustained throughout the interaction.

\subsection{Wave over a bump}

Significant energy transformation was also observed when one wave group encountered a localized, but steep topographic rise (apparent in Fig. $3 \mathrm{~d}$ near $-45 \mathrm{~km}$ ). Wave Isaac was first observed on 10 August 2006 08:50 UTC, as the leading wave began to overtake a second wave group, Holly. 


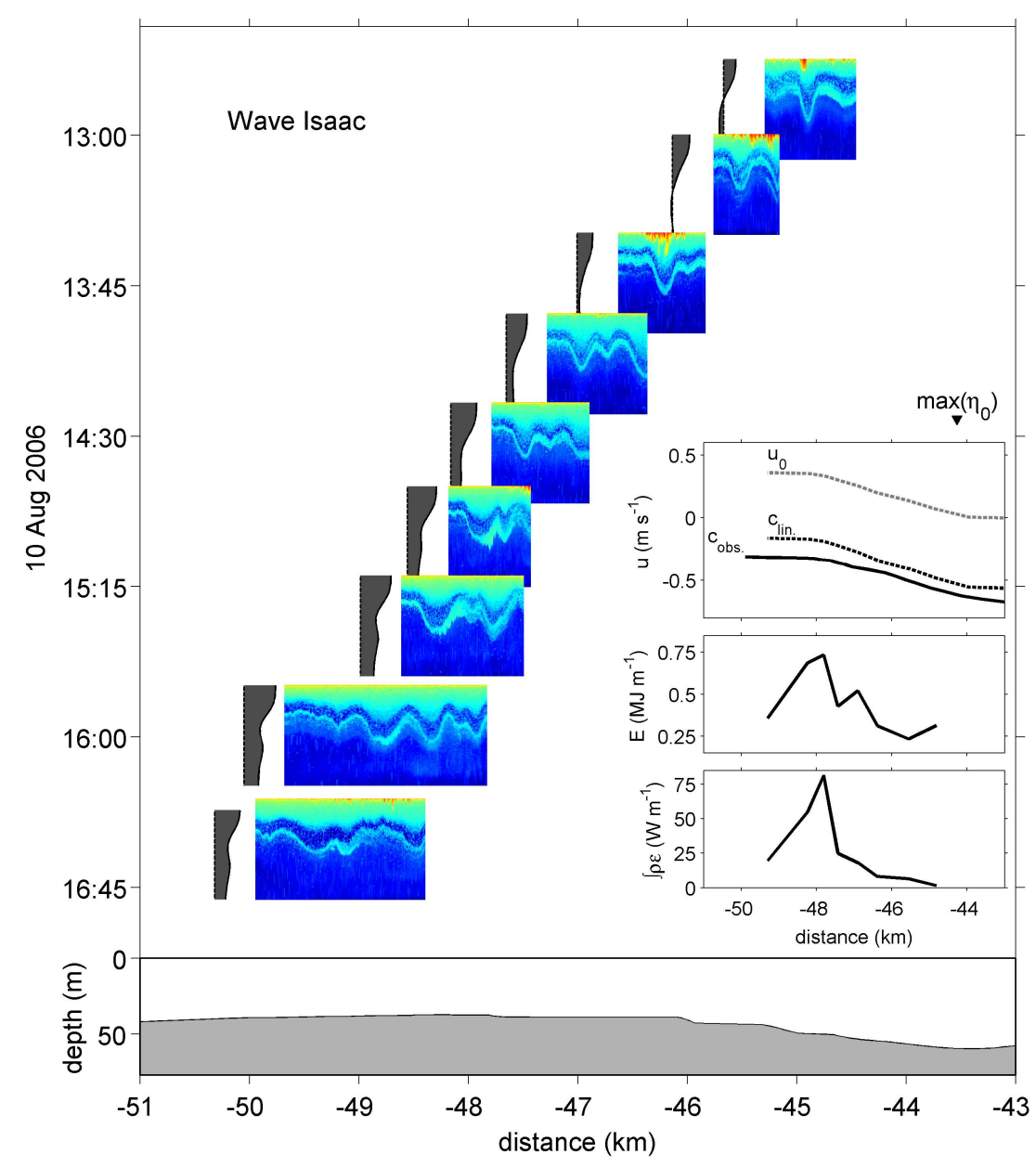

Fig. 14. Acoustic backscatter sequence of Wave Isaac as it encountered a topographic bump. Grey patches to the left of backscatter panels show background velocity profiles ahead of the wave. Top inset panel shows the the observed wave speed (solid black line), linear wave speed (dashed black line), and the depth average of $u_{0}$ (grey dashed line). Positive values are directed offshore. The triangle at top indicates the time of peak tidal elevation, $\eta_{0}$. The middle inset shows the total energy integrated over $750 \mathrm{~m}$ from the leading edge of the first wave, and the bottom inset shows the total dissipative loss integrated over the same distance. The bottom topography is shown in the lower panel.

Initially, Isaac was observed to travel at $-0.8 \mathrm{~m} \mathrm{~s}^{-1}$ with average amplitude of $-8 \mathrm{~m}$, as compared to a speed of $-0.65 \mathrm{~m} \mathrm{~s}^{-1}$ and amplitude near $-4 \mathrm{~m}$ for Holly. Unlike the example of the group-group interaction discussed above for Tonya, Holly and Isaac seemed to propagate independent of one another. The difference may be attributed to either the relatively weak nature of Holly or to the large differences in wave heading. Isaac propagated with a heading of $310^{\circ}$, and Holly maintained a heading of $335^{\circ}$, resulting in a difference of $25^{\circ}$. Due to the character of the two wave groups, the ship abandoned Holly in favor of following the more energetic, Isaac.

At 10 August 2006 12:00 UTC, the leading wave of Isaac encountered a topographic bump in $60 \mathrm{~m}$ of water (Fig. 14). The bump had a steepness of $7 \times 10^{-3}$, with a rise of $20 \mathrm{~m}$ over a $3-\mathrm{km}$ distance. This value can be compared to a mean slope of $5 \times 10^{-4}$ across most of the shelf. As Isaac ap- proached the bump the tidal amplitude, $\eta_{0}$, was near a peak, corresponding to a shift from onshore to offshore barotropic tidal velocity. During this time, the background velocity, $u_{0}$, switched from having an onshore velocity component at depth to being directed offshore at all depths, and the observed onshore wave speed slowed to $-0.3 \mathrm{~m} \mathrm{~s}^{-1}$ (upper inset, Fig. 14). In order to estimate the role of bottom shoaling in the reduction of the shoreward linear wave speed, $c_{0}$ was calculated using the Taylor-Goldstein equation for both i) a quiescent fluid and ii) the fully stratified, sheared background. For case i), the linear wave speed decreased by roughly $10 \%$ between the base of the bump and at its peak. For case ii), $c_{0}$ decreased by $0.44 \mathrm{~m} \mathrm{~s}^{-1}$ during shoaling. This change agrees well with the increase in the offshore barotropic velocity of $0.39 \mathrm{~m} \mathrm{~s}^{-1}$ observed over this time period. Comparison between the two cases emphasizes the importance of advection in this example. 
The increase in the depth-averaged $u_{0}$ can be attributed to two factors. First, as mentioned above the barotropic tidal velocities were moving toward peak offshore amplitudes during the observed time period. The maximum tidal height was achieved at the time that Issac was located at the black triangle in the upper inset of Fig. 14. Over the duration of the wave's transit, offshore tidal velocities continued to increase. Second, mass conservation requires an increase in the barotropic velocity as the water column height decreases over the top of the bump. This second effect, results in an cross-shore gradient in $u_{0}$, which we theorize contributed to the structural and energetic evolution with an effect similar to that explored by Vlasenko and Stashchuk (2006). At any given time, the leading wave, which was always in the shallowest water, encountered the strongest values of $u_{0}$, and as a result the wave was arrested as it approached the crest. However, even in a quiescent fluid this topographic feature would influence the form of the wave. Indeed, the final two backscatter images show a broadening of the leading wave's front face, an anticipated artifact of shoaling.

The total energy integrated over a distance of $750 \mathrm{~m}$ from the leading edge of the first wave more than doubled as the waves appeared to "pile-up" on the bump (middle inset, Fig. 14). (The integration limit was set by the minimum transect distance during this time.) The increase in energy in the wave may in part be explained by the interaction of the mean flow and the waves, as wave amplification is an expected consequence given the orientation of the mean flow, topographic gradient, and wave propagation direction (Vlasenko and Stashchuk, 2006). The convergence of wave energy was accompanied by increased loss to turbulent mixing (bottom inset, Fig. 14). The billows on the trailing edge of the leading wave at $-48.5 \mathrm{~km}$ were well developed, suggesting the importance of shear instabilities. The presence of this localized topographic feature impacts the energetics of Isaac in a similar way that wave interactions induced changes for Tonya and Wyatt, i.e., energy growth followed by dissipative loss to shear-driven turbulence. While only one wave was followed onto the bump, it is possible that any wave encountering this feature under similar background conditions would undergo an analogous transformation. Thus this regional topographic feature may be a geographically localized area of intense NLIW mixing. Note that this discussion has neglected effects associated with reflection and 3-D motions. The latter consideration may be of particular importance, since the length scale of the bump is smaller than the along-crest length scale of the NLIWs.

\section{Summary}

Analysis of NLIW energetics on the New Jersey shelf estimates average NLIW energies on the order of a $\mathrm{MJ} \mathrm{m}^{-1}$. Larger amplitude waves, characterized by a ten-fold increase in energy and doubling of dissipative loss, were observed be- tween 16-22 August 2006. This time-period was not related to the local, barotropic tide, but instead corresponded to a period of increased internal tide energetics (Nash et al., 2010).

The cross-shelf evolution of waves was tracked using shipboard data, which in some cases documented an individual wave's evolution over $50 \mathrm{~km}$ across the shelf. Spatially, the leading three waves in a packet were observed to grow in energy across the outer shelf, after which energy decay was approximately balanced by dissipative loss. Growth is consistent with development of the wave packet from the internal tidal bore; however, other controlling factors such as variations in the background stratification and velocity need further exploration. The total, average dissipative loss over the region of decay scaled with the peak energy in the waves. The resultant decay time scale is estimated as approximately $12 \mathrm{~h}$, corresponding to a length scale of $35 \mathrm{~km}$ (100 wavelengths).

Short-term, rapid energy exchanges occurred as a result of wave interactions and the impingement of a wave group on a small topographic bump. In both cases, the outcome was a significant, rapid energy loss to turbulent mixing. In the case of the interactions, the importance of turbulent mixing and the resultant wave structure suggest that WNL theories or those neglecting mixing may not be adequate to predict wave evolution. In these specific examples, the use of numerical modeling may help shed further light on controlling dynamics.

Acknowledgements. This work was funded by the Office of Naval Research. We thank the Captains, crew and marine technicians of the R/V Oceanus and R/V Knorr for their assistance in the implementation of the ship tracking experiment and the successful deployment and recovery of moorings. Mike Neeley-Brown, Ray Kreth, Alexander Perlin, Greg Avicola, and Sam Kelly helped in obtaining the ship-based observations; and John Kemp, James Lynch, and James Irish were responsible for managing the mooring component. We also thank two anonymous reviewers for their comments and suggestions.

Edited by: A. Scotti

Reviewed by: V. I. Vlasenko and another anonymous referee

\section{References}

Apel, J. R., Holbrook, J. R., Liu, A. K., and Tsai, J. J.: The Sulu Sea Internal Soliton Experiment, J. Phys. Ocean., 15, 1625-1651, 1985.

Brickman, D. and Loder, J. W.: Energetics of the Internal Tide on Northern Georges Bank, J. Phys. Ocean., 23, 409-424, doi:10. 1175/1520-0485(1993)023〈0409:EOTITO $\rangle$ 2.0.CO;2, 1993.

Chang, M.-H., Lein, R.-C., Tang, T. Y., D'Asaro, E. A., and Yang, Y. J.: Energy flux of nonlinear internal waves in northern South China Sea, Geophys. Res. Let., 33, L03607, doi: 10.1029/2005GL025196, 2006.

Colosi, J. A., Beardsley, R. C., Lynch, J. F., Gawarkiewicz, G., Chiu, C.-S., and Scotti, A.: Observations of nonlinear internal waves on the outer New England continental shelf during the 
summer Shelfbreak Primer study, J. Geophys. Res., 106, 95879601, doi:10.1029/2000JC900124, 2001.

Drazin, P. G.: Solitons, 2nd edn., Cambridge University Press, 1984.

Gill, A. E.: Atmosphere-Ocean Dynamics, in: International Geophysics Series, Academic Press, San Diego, California, vol. 30, 219-225, 1982.

Grimshaw, R., Pelinovsky, E., Talipova, T., and Kurkin, A.: Simulation of the transformation of internal solitary waves on oceanic shelves, J. Phys. Ocean., 34, 2774-2791, doi:10.1175/JPO2652.1, 2004.

Hebert, D.: The available potential energy of an isolated feature, J. Geophys. Res., 93, 556-564, doi:10.1029/JC093iC01p00556, 1998.

Holloway, P. E., Pelinovsky, E., Talipova, T., and Barnes, B.: A Nonlinear Model of Internal Tide Transformation on the Australian North West Shelf, J. Phys. Ocean., 27, 871-896, doi:10.1175/1520-0485(1997)027;0871:ANMOIT $; 2.0 . C O ; 2$, 1997.

Inall, M. E., Rippeth, T. P., and Sherwin, T. J.: Impact of nonlinear waves on the dissipation of the internal tidal energy at a shelf break, J. Geophys. Res., 105, 8687-8705, doi:10.1029/1999JC900299, 2000.

Klymak, J. M. and Moum, J. N.: Internal solitary waves of elevation advancing on a shoaling shelf, Geophys. Res. Let., 30, p. 2045, doi:10.1029/2003GL017706, 2003.

Klymak, J. M., Pinkel, R., Liu, C., Liu, A. K., and David, L.: Prototypical solitons in the South China Sea, Geophys. Res. Let., 33, L11607, doi:10.1029/2006GL025932, 2006.

Lamb, K. G.: Energy and pseudoenergy flux in the internal wave field generated by tidal flow over topography, Cont. Shelf Res., 27, 1208-1232, doi:10.1016/j.csr.2007.01.020, 2007.

Lamb, K. G. and Nguyen, V. T.: Calculating Energy Flux in Internal Solitary Waves with an Application to Reflectance, J. Phys. Ocean., 39, 559-580, doi:10.1175/2008JPO3882.1, 2009.

MacKinnon, J. A. and Gregg, M. C.: Mixing on the latesummer New England shelf - Solibores, shear and stratification, J. Phys. Ocean., 33, 1476-1492, doi:10.1175/15200485(2003)033; 1476:MOTLNE; 2.0.CO;2, 2003.

Moum, J., Klymak, J., Nash, J., Perlin, A., and Smyth, W.: Energy Transport by Nonlinear Internal Waves: Experimental Determination, J. Phys. Ocean., 37, 1968-1988, doi:10.1175/JPO3094.1, 2007a.

Moum, J. N. and Smyth, W. D.: The pressure disturbance of a nonlinear internal wave train, J. Fluid Mech., 558, 153-177, doi:10.1017/S0022112006000036, 2006.

Moum, J. N., Gregg, M. C., Lien, R. C., and Carr, M. E.: Comparison of Turbulence Kinetic Energy Dissipation Rate Estimates from Two Ocean Microstructure Profilers, J. Atmos. Ocean. Tech., 12, 346-366, doi:10.1175/15200426(1995)012;0346:COTKED ¿2.0.CO;2, 1995.

Moum, J. N., Farmer, D. M., Smyth, W. D., Armi, L., and Vagle, S.: Structure and Generation of Turbulence at Interfaces Strained by Internal Solitary Waves Propagating Shoreward over the Continental Shelf, J. Phys. Ocean., 33, 2093-2112, doi:10.1175/15200485(2003)033;2093:SAGOTA ¿2.0.CO;2, 2003.
Moum, J. N., Farmer, D. M., Shroyer, E. L., Smyth, W. D., and Armi, L.: Dissipative losses in nonlinear internal waves propagating across the continental shelf, J. Phys. Ocean., 37, 19891995, doi:10.1175/JPO3091.1, 2007b.

Nash, J. D., Alford, M. H., and Kunze, E.: On estimating internal wave energy fluxes in the ocean, J. Atmos. Ocean. Tech., 22, 1551-1570, doi:10.1175/JTECH1784.1, 2005.

Nash, J. D., Shroyer, E., Kelly, S., Moum, J., and Duda, T.: Internal Tides and Nonlinear Internal Waves on the Continental Shelf: Why are they so unpredictable?, in preparation, 2010.

New, A. L. and Pingree, R. D.: Local generation of internal soliton packets in the central Bay of Biscay, Deep Sea Res., 39, 15211534, doi:10.1016/0198-0149(92)90045-U, 1992.

Osborn, T. R.: Estimates of the Local Rate of Vertical Diffusion from Dissipation Measurements, J. Phys. Ocean., 10, 83-89,

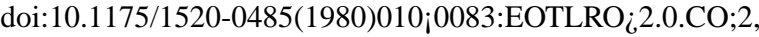
1980.

Ramp, S. R., Tang, T.-Y., Duda, T. F., Lynch, J. F., Liu, A. K., Chiu, C.-S., Bahr, F., Kim, H.-R., and Yang, Y. J.: Internal solitons in the northern South China Sea, Part I: Sources and deep water propagation, IEEE J. Oceanic Eng., 29, 1157-1181, doi:10.1109/JOE.2004.840839, 2004.

Scotti, A., Beardsley, R., and Butman, B.: On the interpretation of energy and energy fluxes of nonlinear internal waves: An example from Massachusetts Bay, J. Fluid Mech., 561, 103-112, doi:10.1017/S0022112006000991, 2006.

Shepherd, T.: A unified theory of available potential energy, Atmos.-Ocean, 31, 1-26, 1993.

Shroyer, E., Moum, J., and Nash, J.: Observations of Polarity Reversal in Shoaling Nonlinear Internal Waves, J. Phys. Ocean., 39, 691-701, doi:10.1175/2008JPO3953.1, 2009.

Shroyer, E., Moum, J., and Nash, J.: Mode-2 waves on the continental shelf: Ephemeral components of the nonlinear internal wave field, J. Geophys. Res., 115, C07001, doi:10.1029/ 2009JC005605, 2010a.

Shroyer, E., Moum, J., and Nash, J.: Nonlinear Internal Waves over New Jersey's continental shelf, J. Geophys. Res., submitted, 2010b.

Small, J., Sawyer, T. C., and Scott, J. C.: The evolution of an internal bore at the Malin shelf break, Ann. Geophys., 17, 547-565, doi:10.1007/s00585-999-0547-x, 1999.

Tang, D. J., Moum, J. N., Lynch, J. F., et al.: Shallow Water '06, Oceanography, 20, 12 pp., 2007.

Turkington, B., Eydeland, A., and Wang, S.: A Computational Method for Solitary Internal Waves in a Continuously Stratified Fluid, Stud. Appl. Math., 85, 93-127, 1991.

Vlasenko, V. and Hutter, K.: Numerical experiments on the breaking of solitary internal waves over a slope-shelf topography, J. Phys. Ocean., 32, 1779-1793, doi:10.1175/15200485(2002)032;1779:NEOTBO ;2.0.CO;2, 2002.

Vlasenko, V. and Stashchuk, N.: Amplification and Suppression of Internal Waves by Tides Over Variable Bottom Topography, J. Phys. Oceanogr., 36, 1959-1973, doi:10.1175/JPO2958.1, 2006.

Winters, K., Lombard, P., Riley, J., and D’Asaro, E.: Available potential energy and mixing in density-stratified fluids, J. Fluid Mech., 289, 115-128, doi:10.1017/S002211209500125X, 1995. 